This is an electronic reprint of the original article. This reprint may differ from the original in pagination and typographic detail.

Author(s): Kokko, Sami

Title: Sports clubs as settings for health promotion: Fundamentals and an overview to research

Year: $\quad 2014$

Version:

Please cite the original version:

Kokko, S. (2014). Sports clubs as settings for health promotion: Fundamentals and an overview to research. Scandinavian Journal of Public Health, 42(Suppl 15), 60-65. https://doi.org/10.1177/1403494814545105

All material supplied via JYX is protected by copyright and other intellectual property rights, and duplication or sale of all or part of any of the repository collections is not permitted, except that material may be duplicated by you for your research use or educational purposes in electronic or print form. You must obtain permission for any other use. Electronic or print copies may not be offered, whether for sale or otherwise to anyone who is not an authorised user. 
Sports clubs as settings for health promotion: Fundamentals and an overview to research

Sami Kokko

Department of Health Sciences, University of Jyväskylä, FI

Corresponding author:

Sami Kokko, Department of Health Sciences, University of Jyväskylä, P.O.Box 35 (L) FI-40014, University of Jyväskylä, Finland.

Email: sami.p.kokko@jyu.fi 


\title{
Sports clubs as settings for health promotion: Fundamentals and an overview to research
}

\author{
Abstract \\ This paper explores the efficacy and value of sports clubs as a setting for health promotion. Sports \\ clubs for children and adolescents are the primary focus of the paper, and the aims are two-fold. Firstly, \\ the paper aims to review the basis for and elements of the health promoting sports club (HPSC) concept. \\ Secondly, the aim is to overview the international evolution of the HPSC concept and its usefulness in \\ the research. The settings-based health promotion approach forms the basis for the HPSC concept and \\ it is introduced first. Thereafter, both obligating and prospecting factors, to justify the importance for \\ sports clubs to address health promotion, are expressed. Major prospecting factors relate to the facts \\ that sports club activities reach a lot of children and adolescents, and that its educational nature is \\ informal due to voluntary participation. The paper also presents multilevel structure of sports clubs, as \\ well as the determinants affecting the settings-based work. The research concerning health promotion \\ in sports-related settings is evolving worldwide, and Nordic countries are in the front line of this new- \\ wave of settings-based health promotion. Indeed, it has been claimed that, for the settings approach to \\ assimilate to current societal challenges, there is a need to widen the reach of the approach to non- \\ traditional, non-institutional settings, like sports clubs.
}

\section{Keywords}

Health promotion, sport, sports club, settings approach 


\section{Introduction}

The settings approach to health promotion has been utilized in settings like cities, schools, hospitals and workplaces for almost thirty years $(1,2)$. The work was for a long time limited to these traditional and institutional settings until other settings were also taken into consideration approximately fifteen years ago (3). Sports-related settings were among the first untraditional settings to be included in this new-wave of settings work. At an early stage, sports venues were examined via advertising change from tobacco products to healthier ones in Australia (4). Thereafter, sports clubs $(5,6,7)$ and associations $(8,9)$ health promotion orientations and activities have been targeted and a healthy stadia network established in Europe (10).

Even though sports clubs serve activities for people at all ages, most of the operations are targeted towards children and adolescents. Therefore, this paper focuses on youth sports clubs. Youth sports clubs possess great potential as a health promotion setting. In Nordic countries, the clubs attract a lot of children and adolescents, forming the largest organized leisure time activity $(11,12,13,14)$. In addition, sports clubs' educational nature is informal; children and adolescents participate in the activities voluntarily, displaying their particular interest in a given sport. By tailoring health messages to relate to a particular sport and sports performance/athlete development, sports club activities may form a highly-motivating health promotion context for youth. Even so, to date, youth sports clubs have only been targeted and studied as health promoting settings to a limited degree. The aims of this paper are to firstly highlight the elements of the health promoting sports club (HPSC) concept, and secondly, to overview the evolution and usefulness of the HPSC concept internationally.

\section{Argumentation for sports clubs to pay attention to health promotion}

On the basis of the literature, youth sports clubs can be seen to have both obligations and prospecting factors to acknowledge and act on health promotion $(6,15)$. Obligations are more moral and ethical by nature, because the most of the clubs in Nordic countries are based on voluntary civil activity, which can only be guided, not obligated per se.

The first obligation relates to the fact that the state financially subsidizes national sport associations and municipalities similarly subsidize local clubs. From this perspective, sports associations and clubs have a semi-official status (16), and public administration can expect reciprocity i.e. clubs to pay attention to publicly important issues like the promotion of health. Moreover, voluntary organizations have been 
seen particularly potential contexts to enhance interactions between the state and individuals i.e. to mediate information, values etc. mutually (17).

The fundamentals of the voluntary activities and the historical development of sports clubs form the second obligation. Voluntary activity should contribute to the needs of its participants (18). In sports club activities, this does not always happen, as the competitive objectives overpower other aims (19). The historical perspective addresses the values and fundamentals the club activities initially possessed. Many of the Finnish sports clubs were founded for some other reason than purely sports i.e. under labour associations and temperance societies. Sport was used as a vehicle through which other ideological values, especially temperance, were pursued. A non-drinking, honest and vigorous person has been, and continues to be, the paragon of a sportsman, especially in junior sport. The historical development of civil activity in other Nordic countries shapes similarly the national fundamentals behind the club activities (13).

The third obligation concerns the sports clubs' and officials' argument that health education and/or promotion is the responsibility of homes and parents, not clubs (15). This raises a fundamental question of whether club actors can operate with children and adolescents without any responsibility beyond sport? Due to the authoritative role of all the adults, but coaches in particular, it is evident that they cannot. Also, the clubs are integral, not external, part of surrounding societies (16). Therefore, problems in public health concern every actor in the society, which under health promotion mean shared responsibility, instead of government taking care of the problems alone (16)..

The fourth obligation arises from the paradox in the operational principles of youth sports clubs and the health promotion activities of the clubs and coaches. The majority of the sports clubs proclaim to have other features beyond sports in their agenda. In Finland, almost all of youth clubs state that healthy lifestyle is an important goal for them (20). However, the research indicates that both the clubs and coaches have not paid attention to health promotion (15). Also, some negative trends in health behaviours among sports club participants' conflict with the club-level aims on healthy lifestyle (15). Thus, there is a need for clubs and coaches to invest more time and effort on these other, non-sports features.

The fifth obligation relates to the injury risk in sports. Fundamentally, when the level of physical activity increases, the risk of different kinds of injuries also increases (e.g. 21, 22). Injuries, especially 
serious ones, are major events for a developing youth, with both physical and mental effects. Thus, sports clubs have, at least a moral obligation, to invest in both injury prevention and comprehensive treatment of injuries.

In addition to these obligating arguments, there are also prospecting factors for youth sports clubs to invest in health promotion (15). Firstly, sports club activities reach and involve a large number of children and adolescents in Nordic countries. Thus, the impact is notable. Secondly, when children and adolescents are participating in club activities on voluntarily-basis and by their own interest, the informal educational nature allows health issues to be applied to a given sport and therefore become more interesting for the youth. Thirdly, youth sports coaches are important authority figures for children and youth. Thus, they have great potential to influence health issues if so desired.

The fourth prospecting factor is that, by investing in health promotion, a club responds to the societal claim for the third sector (clubs) to share its responsibility for public health. Still, at the same time, a club first and foremost enhances its core-aims of optimizing sports performance and athlete development. To highlight the latter issue further, health is fundamental for everyone, but especially important for athletes. The significance of the lifestyle factors to athlete development can be demonstrated by describing the effects of un-healthy behaviors. For example, a shortage in sleep, unbalanced diet, usage of substances, a large amount of screen time, and over-usage of energy drinks all decrease psychophysical alertness for training, disturb learning and slow up recovery from training. Also, indirect effects, such as a lack of adequate sleep leads to tiredness, which again leads to feelings of dizziness, restlessness, hyperactivity and unbalanced moods and subsequently reduce the optimal training effect. Clarification of these linkages to coaches would presumably enhance the coaches' interest and activities on surrounding health issues.

\section{Health promotion in youth sports clubs: theoretical grounds}

The theoretical foundation of the health promoting sports club (HPSC) concept is based on the settings approach to health promotion. This approach highlights the whole system of the setting. The activities

of any organizational setting can be divided into three levels - macro, meso and micro (3). For a sports club setting, macro level encompasses the overall policies and orientation of activities of a club. Meso level relates to the activities managed by the leading persons in a club, namely the club officials. The activities on the meso level are often designed to guide, alter or support the micro-level actors. Micro 
level refers to corresponding activities by the practitioners, namely the coaches, in guiding, altering or supporting the actions of the club members; the young athletes in this case.

The key-question when acting on the settings-based principles is; what kind of preconditions the preceding level at clubs sets out for the next level (actors/participants)? For example, what kind of preconditions the club (setting) sets out for its coaches (actors) to execute health promotion? Or at micro level, what should the coaches do beforehand to influence athlete behavior (individual action)? As an example, health promotion activities appear at each level and mutually reinforce each other through policies and reward systems. Basically, health promotion should be acknowledged and acted on simultaneously at every level to reach the best possible impact.

Overall, the settings approach to health promotion strives for changes in the structure and ethos of a setting; in this case in sports clubs and in the subject of health promotion. This, in turn, means that all cultural, social, economic and environmental determinants at all levels within the setting in question need to be noticed (figure 1). Cultural determinants relate to, for example, what kind of status health promotion has in the clubs policies and operational principles and social determinants to how socially accepted it is to invest in health promotion. Economic determinants highlight the importance to allocate both financial and practical (time and knowhow) resources to health promotion and environmental determinants the physical and social conditions in which the daily activities take place. Together with these settings-based determinants it should be remembered that the influence between a setting and people is not one-way. Reciprocal determinism refers therefore to the fact that together when the settings-based factors set limits on possible behavioral forms, the behaviors and actions by people within that setting also influence the setting (figure 1). 


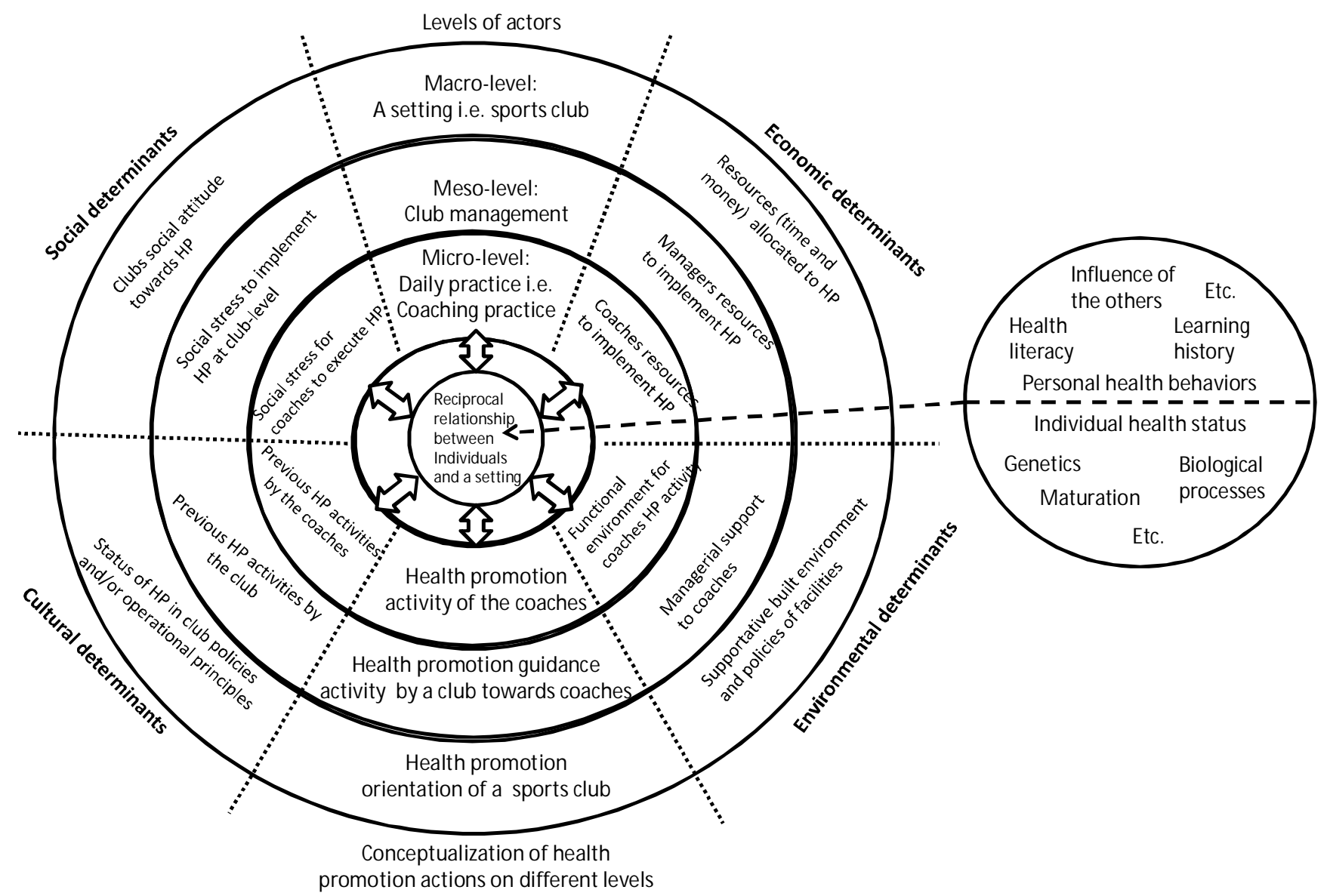

Figure 1 Determinants of settings-based health promotion and reciprocal interaction of setting- and individual-based factors within a sports club setting (3). HP = Health Promotion.

\section{HPSC research: Nordic, European and international perspectives}

Health promotion in the sport setting started to evolve in the mid 1990's, when the effectiveness of sponsoring and advertising targeted on peoples' health behaviours at sports venues was focussed (4, 23). At that time, tobacco sponsoring and advertising was prohibited in Australia and replaced by equivalent promotion of health products and services. More recently, in Australia, an alcohol-use prevention program within sports clubs - the Good Sports Program - was launched in 2000 in the state of Victoria. Today, the Good Sports Program reaches almost 6000 clubs (24). The program follows the principles of the settings approach and has been proven effective (25). Victoria's sports clubs' healthrelated policies have also been examined (5). Currently, there are several research groups working with 
different themes within sports and health promotion, like sports clubs as healthy and welcoming environments in order to increase member volume (7), sports clubs and associations health promotion activities with special focus on nutrition-related activities (8), health promotion within sports and recreation organizations with focus on capacity building strategies (9) and sports injury prevention related research (26). The HPSC conceptualizations and/or measurements have been proven useful and reliable (27) in assessing the health promotion actions in Australian sporting organizations and those have also been developed and applied further.

In Europe, the concept of the HPSC was introduced in 2004, when the theoretical background for the concept was first compiled (6). With these fundamentals, the concept of the HPSC has so far been used to review the current status of health promotion among youth sports clubs in some European countries (28-30) plus Australia (8-9). The European studies have used HPSC concept and measurements successfully and indicate fairly consistently that youth sports clubs and/or coaches on an average orientate positively on health promotion, but the positivism has not yet been converted into practical activity; neither by the clubs nor coaches (28-30). It is especially true, that the comprehensive perspective still appears to be a faraway goal for many of the sports clubs. Indeed, at the moment, both the clubs guidance activity and coaches' implementation on health promotion is relatively common with relation to issues close to sports performance, but much less active concerning non-performancerelated health issues (15). On the other hand, it seems that comprehensive health promotion orientation at the club-level generates a higher level of health promotion activity in practice (15).

The Australian studies have focussed on national and/or regional sport organizations, not clubs per se. With this notion, the results indicate that there is a wide variation between health-issues noticed in the operational principles of these sports organizations. The issues like social inclusion is quite well established, whereas others, like sun protection and nutritional issues, less so (8). It also seems, that the capacity of different organizations to invest in health promotion varies considerably, depending on for example the magnitude of an organization or on how important the societal responsibility was perceived (9).

When looking at more focused the situation of the HPSC work in Nordic countries, the development started in Finland (28) as stated earlier, but has evolved in other countries too. In Sweden, for example, the importance of "the plethora of actors in the health-promoting youth sports clubs' network" has been emphasized (29 p.13). In Norway, sports clubs have been reviewed as settings for sport policy 
implementation (which also has health-related aims) with an emphasis on the local characteristics and volunteers (13). In Denmark, there is no clear model of HPSC. Instead a similar ideology - ecologicalbased model - has been used around the talent development (31).

Elsewhere in Europe Belgium (32), France (30) and Ireland (33) have followed the Nordic route and HPSC concept and are measuring the health promotion activities of the sports clubs and/or the coaches, and the work in these countries is currently in progress. In the Netherlands, a special focus has been targeted to tennis clubs with the themes of provision of healthy foods, injury prevention and treatment, social health, and safety around the clubs (34).

The model of HPSC has, to date, been mainly used as a research tool for describing the current situation among youth sports clubs. On the basis of the results, some guidelines to support the health promotion development in clubs have been created (35). Some clubs have started their development work and many have been interested. The future work in this field should concentrate on creating feasible, effective and long-lasting interventions, which should be scientifically evaluated. Valid and reliable tools for this evaluation should also be created and tested.

Finally, another sport-related concept, namely he Healthy Stadia concept, was initiated in 2004 in the UK (36). A Healthy Stadium can be defined as: “...one which promotes the health of visitors, fans, players, employees and the surrounding community. It is a place where people can go to have a positive healthy experience playing or watching sport." (36, p.4). A European network for the Healthy Stadia was established in 2007 and has an increasing amount of sport stadiums and collaborating partners from several European countries (10). Yet, from the Nordic countries only two Finnish stadiums are participating in this network. One challenging factor at sports stadiums is the conflict of interests in it, as health promotion strategies are often opposed to marketing strategies (10).

\section{Conclusions}

Under the settings approach to health promotion, a claim for wider recognition and utilization of nontraditional, non-institutional settings was recently made (37). Indeed, the work around the approach was for a long time focused on traditional setting initiatives and new initiatives, sports-related among others, were overlooked. Sports-related settings have their strengths, limitations and challenges from a health promotion perspective. Still, the obligating and prospecting factors presented in this paper highlight that the investment in health promotion, by the sports clubs, actually supports their core- 
businesses of sports performance and athlete development while simultaneously correspond to the demands set by the surrounding societies.

The HPSC concept emphasizes firstly, the recognition of the whole system of a sports club, secondly, various levels of activities (on macro, meso, micro levels), and thirdly, the preconditions the upper level generates for the next one. The settings approach also highlight that there are several determinants of health relating to social, cultural, economic and environmental conditions that have an effect on the position of health promotion in the given setting (figure 1). These determinants serve also as examples of factors that need to be addressed in the settings-based work in a sports club setting.

Nevertheless, when working with a setting that is not fundamentally health-based, it is crucial to recognise the core-business of the setting in question (i), identify a link between the core-business and health promotion (ii), and use the language and wording commonly used in that setting (iii). In a sports club context these mean that it should be kept in mind that sports clubs operate mainly to organise sports activities and to develop athletes (i) and that the clear link between health/health behaviours and sports performance and athlete development should be emphasized (ii). This can be proven as demonstrated in the text through un-healthy examples. The usage of sports-related language may make the health-issues more understandable and motivating (iii).

The research around HPSC is emerging in Nordic, European and international levels, Australia currently being the leading country. Nordic countries are, yet to varying degrees, on the crest of the wave of the new wave of the settings-based health promotion. But still, the work around HPSC is only taking its first steps. Therefore, a repetition from the beginning of the conclusions is in order: under the settings approach to health promotion there is a need to invest beyond the traditional settings initiatives - "...in order to ensure that the settings approach responds to societal changes and addresses inequalities, we need to extend its reach into non-traditional, non-institutional settings..." (37 p. 47)!

\section{References}

1. Golden SD, Earp JA. Social ecological approaches to individuals and their contexts: twenty years of Health Education \& Behavior health promotion interventions. Health Education \& Behavior. 2012; 39, 364-72.

2. Richard L, Gauvin L, Raine K. Ecological Models Revisited: Their Uses and Evolution in Health Promotion Over Two Decades. Annual Review of Public Health. 2011; 32, 7.1-7.20. 
3. Kokko S, Green LW, Kannas L. A review of settings-based health promotion with applications to sports clubs. Health Promotion International. 2013. First published online June 30, 2013 doi:10.1093/heapro/dat046 (16 pages).

4. Giles-Corti B., Clarkson J.P., Donovan R.J., Frizzell S.K., Carroll A.M., Pikora T., Jalleh G. Creating smoke-free environments in recreational settings. Health Education \& Behavior. 2011; 28, 341-51.

5. Dobbinson S.J., Hayman J.A., Livingston P.M. Prevalence of health promotion policies in sports clubs in Victoria, Australia. Health Promotion International. 2006; 21, 121-9.

6. Kokko S. Sports clubs as a setting for youth health promotion. In Hoikkala T., Hakkarainen P., Laine S. (eds.) Beyond health literacy. Youth cultures, prevention and policy. 2005; Finnish youth research network / Finnish youth research society publications 52, 338-54.

7. $\quad$ Eime R.M., Payne W.R., Harvey J.T. Making sporting clubs healthy and welcoming environments: A strategy to increase participation. Journal of Science and Medicine in Sport. 2008; 11, 146-54.

8. Kelly B., Baur L.A., Bauman A.E., Smith B.J., Saleh S., King L.A., Chapman K. Health promotion in sport: An analysis of peak sporting organisations' health policies. Journal of Science and Medicine in Sport. 2010; 13, 566-7.

9. Casey M.M., Payne W.R., Eime R.M., Brown S.J. Organisational readiness and capacity building strategies of sporting organisations to promote health. 2012. Sport Management Review; 15, 10924.

10. Drygas W., Ruszkowska J., Philpott M., Björkström O., Parker M., Ireland R., Roncarolo F., Tenconi M. Good practices and health policy analysis in European sports stadia: results from the 'Healthy Stadia' project. 2013; 28, 157-65.

11. Geidne S., Quennerstedt M., Eriksson C. The implementation process of alcohol policies in eight Swedish football clubs. Health Education. 2013; 113, 196-215.

12. Vilhjalmsson R., Kristjansdottir G. Gender differences in physical activity in older children and adolescents: the central role of organized sport. Social Science \& Medicine. 2003; 56, 363-374.

13. Skille E.A. Competitiveness and health: The work of sport clubs as seen by sport clubs representatives - a Norwegian case study. International Review for the Sociology of Sport. 2010; $45,73-85$.

14. Heinemann K. Sports clubs in Europe. In Heinemann K. (ed.) Sport clubs in various European countries. Series Club of Cologne, Vol 1. Stuttgart: Hofmann Verlag and Schattauer. 1999; 13-32.

15. Kokko S. Health Promoting Sports Club - Youth Sports Clubs' Health Promotion Profiles, Guidance, and Associated Coaching Practice, in Finland. University of Jyväskylä, Studies in Sport, Physical Activity and Health 144; 2010.

16. Heikkala J. Ajolähtö turvattomiin kotipesiin [Bases loaded for unsafe home bases]. Tampereen yliopisto (University of Tampere). Acta Universitatis Tamperensis 641; 1998.

17. Rütten A., Abu-Omar K., Levin L., Morgan A., Groce N., Stuart J. Research note: Social catalysts in health promotion implementation. Journal of Epidemiology and Community Health. 2008; 62, 560-5.

18. Thiel A., Mayer J. Characteristics of voluntary sports clubs management: A sociological perspective. European Sport Management Quarterly. 2009; 9, 81-98.

19. Gilbert W.D., Trudel P. Role of the coach: How model youth team sport coaches frame their roles. The Sport Psychologist. 2004; 18, 21-43.

20. Koski P. Liikunta- ja urheiluseurat muutoksessa [Sports clubs in change]. SLU-julkaisusarja 7. Helsinki: SLU-paino. 2009. 
21. Hernelahti M., Heinonen O.J., Karjalainen J., Nylander E., Börjesson M. Sudden cardiac death in young athletes: time for a Nordic approach in screening? Scand J Med Sci Sports. 2008; 18, 132139.

22. Parkkari J., Pasanen K., Mattila V.M., Kannus P., Rimpelä A. The risk for a cruciate ligament injury of the knee in adolescents and young adults: a population-based cohort study of 46500 people with a 9 year follow-up. Br J Sports Med. 2008; 42, 422-426.

23. Corti B., Holman C. D. J., Donovan R. J., Frizzell S. K., Carroll A. M. Using sponsorship to create health environments for sport, racing and arts venues in Western Australia. Health Promotion International. 1995; 10, 185-97.

24. Duff C., Munro G. Preventing alcohol-related problems in community sports clubs: The good sports program. Substance Use \& Misuse. 2007; 42, 1991-2001.

25. Rowland B., Allen F., Toumbourou J.W. Impact of Alcohol Harm Reduction Strategies in Community Sports Clubs: Pilot Evaluation of the Good Sports Program. Health Psychology. 2012; 31, 323-33.

26. Donaldson A., Finch C.F. Applying implementation science to sports injury prevention. British Journal of Sports Medicine published online March 16, 2013. doi: 10.1136/bjsports-2013-092323.

27. Casey M., Harvey J., Eime R., Payne W. The test-retest reliability of a health promotion assessment tool in sport. Annals of Leisure Research. 2011; 14, 304-324.

28. Kokko S, Kannas L, Villberg J. Health promotion profile of youth sports clubs: club officials' and coaches' perceptions. Health Promotion International. 2009: 24, 26-35.

29. Geidne S, Quennerstedt M, Eriksson C. The youth sports club as a health-promoting setting: An integrative review of research. Scandinavian Journal of Public Health. 2013. Published online before print January 24, 2013, doi: 10.1177/1403494812473204.

30. Van Hoye A, Sarrazin P, Kokko S, Heuzé JP. Coaches' perceptions of French sport clubs: health promotion activities, aims, and coach motivation. Health Education Journal. 2014. Accepted.

31. Henriksen K., Stambulova N., Roessler K.K. Holistic approach to athletic talent development environments: A successful sailing milieu. Psychology of Sport and Exercise. 2010; 11, 212-22.

32. Meganck J., Seghers J.University of Leuven, Belgium. Un-published.

33. Aoife L, Niamh, M. Evaluation framework for Ireland's GAA healthy club initiative. Book of abstracts for the $4^{\text {th }}$ Conference of HEPA Europe, Helsinki, Finland. 2013, page 39.

34. Pluim B.M., Earland J., Pluim N.E. The development of healthy tennis clubs in the Netherlands. British Journal of Sports Medicine published online January 30, 2013. doi:10.1136/bjsports-2012091567.

35. Kokko S. Guidelines for youth sports clubs to develop, implement and assess health promotion within its activities. Health Promotion Practice published online 19 December 2013, DOI: 10.1177/1524839913513900 (10 pages).

36. Crabb J., Ratinckx L. The healthy stadia initiative. Department of Health: North West Public Health Team. 2005.

37. Dooris M. Expert voices for change: Bridging the silos - towards healthy and sustainable settings for the 21st century. Health \& Place. 2013; 20, 39-50. 